\title{
BUDAYA ORGANISASI DAN MOTIVASI KERJA DAN KAITANNYA DENGAN
} KINERJA GURU

\author{
Arwadi $^{1}$, Ruhita ${ }^{2}$ \\ ${ }^{1}$ Sekolah Menengah Kejuruan Gantar, Jln. Raya Haurgeulis - Gantar km. 06, Indramayu, Jawa \\ Barat Indonesia, arwadialdatami@gmail.com, \\ ${ }^{2}$ Universitas Wiralodra, Jl. Ir. H. Juanda KM 3 Indramayu, Jawa Barat-Indonesia \\ ruhitapasca@unwir.ac.id
}

Received Desember 14, 2018, reviewed January 20, 2019, published Maret 30, 2019

Citation: arwadi. (2019). Budaya Organisasi dan Motivasi Kerja dan Kaitannya Dengan Kinerja Guru (Studi Deskriptif Analitik pada Guru Sekolah Menengah Pertama Negeri di Sektor 5 Kabupaten Indramayu). Edum Journal, Vol 2, No 1, Hal 44-53, Maret 2019.

DOI:

\begin{abstract}
ABSTRAK
Penelitian ini bertujuan untuk untuk menggali lebih jauh mengenai kondisi budaya organisasi dan motivasi kerja guru serta pengaruhnya terhadap kinerja guru sekolah menengah pertama (SMP) Negeri pada Sektor 5 di Kabupaten Indramayu. Jenis penelitian ini yakni deskriptif analitis. Populasi dalam penelitian ini adalah seluruh guru SMP Negeri pada Sektor 5 di Kabupaten Indramayu Jumlah guru pada SMP Negeri di Sektor 5 Kabupaten Indramayu adalah 420 orang jumlah sampel yaitu guru SMP Negeri pada Sektor 5 di Kabupaten Indramayu sebanyak 81 orang. Analisis data dalam penelitian ini menggunakan analisis data deskriptif dan regresi berganda. Hasil penelitian menginformasikan bahwa: (1) terdapat pengaruh positif dan signifikan antara budaya organisasi terhadap kinerja guru pada SMP Negeri di Sektor 5 Kabupaten Indramayu, serta besarnya kontribusi sebesar 7,4 \%. (2) terdapat pengaruh positif dan signifikan antara motivasi kerja guru terhadap kinerja guru pada SMP Negeri di Sektor 5 Kabupaten Indramayu, serta (2) besarnya kontribusinya sebesar $19 \%$. (3) terdapat pengaruh positif dan signifikan antara budaya organisasi dan motivasi kerja guru secara bersama-sama terhadap kinerja guru pada SMP Negeri di Sektor 5 Kabupaten Indramayu, serta (2) besar kontribusinya sebesar $22,9 \%$, sementara sisanya dipengaruhi faktor lain yang tidak dibahas dalam penelitian ini.
\end{abstract}

Kata Kunci: Budaya Organisasi, Motivasi Kerja, Kinerja Guru

\begin{abstract}
This study aims to explore more about the conditions of organizational culture and work motivation of teachers and their influence on the performance of State Junior High School (SMP) teachers in Sector 5 in Indramayu Regency. This type of research is descriptive analytical. The population in this study were all state junior high school teachers in Sector 5 in Indramayu District. The number of teachers in the Public Middle School in Sector 5 of Indramayu Regency was 420 people, namely 81 junior high school teachers in Sector 5 in Sector 5 in Indramayu Regency. Data analysis in this study used descriptive data analysis and multiple regression. The results of the study inform that: (1) there is a positive and significant influence between organizational culture on teacher performance in the Public Middle School in Sector 5 of Indramayu Regency, and the amount of contribution is $7.4 \%$. (2) there is a positive and significant influence between teacher work motivation on teacher performance in the Public Middle School in Sector 5 of Indramayu Regency, and (2) the amount of contribution is $19 \%$. (3) there is a positive and significant influence between organizational culture and teacher work motivation together on the performance of teachers in the Public Middle School in Sector 5 of Indramayu Regency, and (2) the contribution is $22.9 \%$, while the rest is influenced by other factors that do not discussed in this study.
\end{abstract}

Keywords: Organizational Culture, Work Motivation, Teacher Performance 
PENDAHULUAN

Sekolah merupakan tempat terjadinya proses pendidikan secara formal. Setiap proses belajar mengajar diharapkan mampu mengembangkan peserta didik sehingga tercapai tujuan pendidikan (Munirah, 2015). Pelaksanaan proses pembelajaran dapat terlaksana dengan baik apabila faktor-faktor yang berkaitan dengan kegiatan pembelajaran seperti peserta didik, pendidik, sarana dan prasarana pendidikan saling mendukung dan guru mampu bersenergi dengan baik (Falah, 2015).

Sebagai suatu proses, guru merupakan jabatan yang memerlukan keahlian khusus sebagai pendidik dan tidak dapat dilakukan oleh sembarang orang di luar bidang pendidikan (Nurfaidah \& Musa, 2016). Sampai saat ini penguasaan kompetensi yang harus dimiliki oleh seorang guru masih dirasakan kurang. Tuntutan terhadap kinerja guru selain didukung oleh kompetensi guru, tidak akan dapat terpenuhi tanpa didukung juga oleh budaya organisasi yang kondusif (Hasibuan, 2016).

Kinerja guru yang tinggi dipengaruhi oleh berbagai faktor, di antaranya: pengawasan dari kepala sekolah sebagai pimpinan, iklim atau suasana kerja yang nyaman, fasilitas pembelajaran terpenuhi sebagaimana tuntutan kurikulum, budaya kerja yang mendorong terwujudnya

kenyamanan dalam bekerja, serta motivasi dan kompensasi (Zufani, dkk, 2017). Dengan tidak bermaksud mengecilkan makna pengaruh yang lain, karena keterbatasan pengetahuan, kemampuan dan waktu penulis, dalam penelitian ini hanya dua variabel yang dibahas pengaruhnya, yaitu: budaya organisasi dan motivasi kerja guru.

Untuk membentuk budaya organisasi (sekolah) yang efektif, seluruh pemangku kepentingan di sekolah perlu memahami dan bergerak dalam suatu kesamaan visi dan misi sekolah (Sutjipto, 2011). Kebudayaan sekolah harus kondusif dengan memperhatikan berbagai potensi bagi pemberdayaan segenap sumber daya yang ada secara optimal dan memberikan kesempatan bagi setiap personil untuk berkreasi dan berinovasi di dalam pelaksanaan tugasnya sesuai dengan visi dan misi sekolah tersebut (Zahroh, 2015). Dengan demikian kebudayaan yang positif akan mempengaruhi pengembangan diri dan kompetensi profesional setiap personil dalam upaya proses peningkatan mutu sekolah khususnya dan mutu pendidikan secara umum (Rasmi, 2014).

Selain budaya organisasi, ada faktor psikologis yang cukup memberikan 
kontribusi bagi tercapainya kinerja guru yang bagus yaitu motivasi kerja guru. Motivasi merupakan faktor pendorong terwujudnya semangat kerja yang tinggi. Guru dengan motivasi kerja yang tinggi terlihat dari kehadiran tidak pernah terlambat dan tidak pernah absen tanpa alasan yang kuat, guru dalam bekerja tidak memerlukan pengawasan yang ketat karena guru merasa bertanggung jawab (Sukamto \& Pardjono, 2016).

Berdasarkan uraian diatas, timbul niat penulis untuk menggali lebih jauh mengenai kondisi budaya organisasi dan motivasi kerja guru serta pengaruhnya terhadap kinerja guru sekolah menengah pertama (SMP) Negeri pada Sektor 5 di Kabupaten Indramayu.

\section{METODE PENELITIAN}

Jenis penelitian ini yakni deskriptif analitis, dengan menggunakan metode survey deskriptif adalah suatu metode penelitian yang mengambil sampel dari suatu populasi dan menggunakan kuesioner sebagai alat pengumpulan data.

Dalam penelitian ini, variabel yang diukur terdiri dari dua buah variabel bebas dengan notasi $\left(\mathrm{X}_{1}\right)$ dan $\left(\mathrm{X}_{2}\right)$, dan satu buah variabel terikat dengan notasi (Y). Adapun variabel-variabel tersebut adalah variabel bebas (independent variabel) dengan notasi $\left(\mathrm{X}_{1}\right)$ yaitu budaya organisasi dengan dimensi: (1) Inovasi dan pengambilan resiko, (2) Perhatian terhadap kerincian, (3) Orientasi pada hasil, (4) Orientasi pada individu, (5) Orientasi pada tim, (6) Keagresifan, (7) Kemantapan (Robbins, 2005).

Variabel bebas (independent variabel) yang kedua dengan notasi $\left(\mathrm{X}_{2}\right)$ yaitu motivasi kerja guru dengan dimensi: 1) Motivasi internal atau motivasi intrinksik dan (2) Motivasi eksternal atau motivasi ekstrinksik (Marwansyah \& Mukaram, 2002)

Variabel terikat (dependen variabel) dengan notasi (Y), yaitu variabel yang dipengaruhi atau menjadi akibat adanya variabel bebas (independent variable). Variabel tersebut adalah kinerja guru dengan dimensi: (1) Rasional, (2) Konsisten, (3) Tepat dan jelas, (4) Efisien, (5) Terarah, (6) Tertantang, (7) Sistematis, (8) Mencapai target, (9) Disepakati, (10) Terkait dengan waktu, (11) Disiplin (Dale, 2001).

Populasi dalam penelitian ini adalah seluruh guru SMP Negeri pada Sektor 5 di Kabupaten Indramayu Jumlah guru pada SMP Negeri di Sektor 5 Kabupaten Indramayu adalah 420 orang jumlah sampel yaitu guru SMP Negeri pada Sektor 5 di Kabupaten Indramayu sebanyak 81 orang. teknik pengumpulan data yang penulis gunakan dalam penelitian ini adalah 
observasi, studi literatur, wawancara dan angket.

Kegiatan yang cukup penting dalam keseluruhan proses penelitian adalah pengolahan data. Dengan pengolahan data dapat diketahui tentang makna dari data yang berhasil dikumpulkan. Dengan demikian hasil penelitian pun akan segera diketahui. Dalam pelaksanaannya, pengolahan data dilakukan melalui bantuan komputer dengan program SPSS (Statistical Product and Service Solution) versi 22.

Langkah-langkah atau prosedur pengolahan data yang dilakukan dalam penelitian ini adalah sebagai berikut: (1) menyeleksi data agar dapat diolah lebih lanjut, yaitu dengan memeriksa jawaban responden sesuai dengan kriteria yang telah ditetapkan; (2) menentukan bobot nilai untuk setiap kemungkinan jawaban pada setiap item variabel penelitian dengan menggunakan skala penilaian yang telah ditentukan, kemudian menentukan skornya;
(3) melakukan analisis secara deskriptif, untuk mengetahui kecenderungan data. Dari analisis ini dapat diketahui rata-rata, median, standar deviasi dan varians data dari masingmasing variabel; (4) melakukan regresi sederhana dan berganda.

\section{HASIL PENELITIAN DAN}

PEMBAHASAN

\section{Pengaruh Budaya Organisasi $\left(\mathrm{X}_{1}\right)$} terhadap Kinerja Guru (Y)

Untuk mengetahui besaran pengaruh budaya organisasi $\left(\mathrm{X}_{1}\right)$ secara individual (parsial) terhadap kinerja guru (Y) dapat dilihat dari nilai t pada tabel Coefficients dibawah ini dengan kriteria pengujian jika tingkat signifikansi lebih kecil dari 0,05, maka hipotesis diterima. Adapun hasil pengujian hipotesis tersebut adalah sebagai berikut:

Tabel 4.13

\section{Uji Hipotesis ( $t$ ) Variabel $X_{1}$ terhadap $Y$}

Coefficients $^{\mathbf{a}}$

\begin{tabular}{|c|c|c|c|c|c|c|}
\hline \multirow{2}{*}{\multicolumn{2}{|c|}{ Model }} & \multicolumn{2}{|c|}{$\begin{array}{c}\text { Unstandardized } \\
\text { Coefficients }\end{array}$} & \multirow{2}{*}{$\begin{array}{c}\text { Standardized } \\
\text { Coefficients } \\
\text { Beta }\end{array}$} & \multirow[b]{2}{*}{$\mathrm{t}$} & \multirow[b]{2}{*}{ Sig. } \\
\hline & & $\mathrm{B}$ & Std. Error & & & \\
\hline 1 & (Constant) & 48,720 & 9,614 & & 5,068 &, 000 \\
\hline & Budaya_Organisasi_X1 & ,397 & , 146 & ,272 & 2,730 & 008 \\
\hline
\end{tabular}

a. Dependent Variable: Kinerja_Guru_Y

Berdasarkan tabel hasil uji $t$ organisasi $\left(\mathrm{X}_{1}\right)$ memiliki nilai sebesar $p$ diperoleh bahwa nilai $t_{\text {hitung }}$ variabel budaya signifikan. Hal tersebut berarti budaya 
organisasi $\left(\mathrm{X}_{1}\right)$ secara parsial berpengaruh terhadap kinerja guru (Y). Hal tersebut berarti menerima hipotesis yang menyatakan: "Terdapat pengaruh positif dan signifikan budaya organisasi terhadap kinerja guru pada SMP Negeri di Sektor 5 Kabupaten Indramayu ".

Persamaan regresi dari hasil perhitungan diperoleh $\hat{y}=48,720+$
0,397X $X_{1} \quad$ Konstanta sebesar 48,720 menyatakan bahwa jika ada kenaikan nilai dari variabel budaya organisasi $\left(\mathrm{X}_{1}\right)$, maka kinerja guru (Y) adalah 48,720. Koefesien regresi sebesar 0,397 menyatakan bahwa setiap perubahan satu skor atau nilai budaya organisasi akan memberikan skor 0,397.

Tabel 1

Signifikansi Pengaruh Variabel $\mathrm{X}_{1}$ terhadap Y ANOVA $^{\mathrm{a}}$

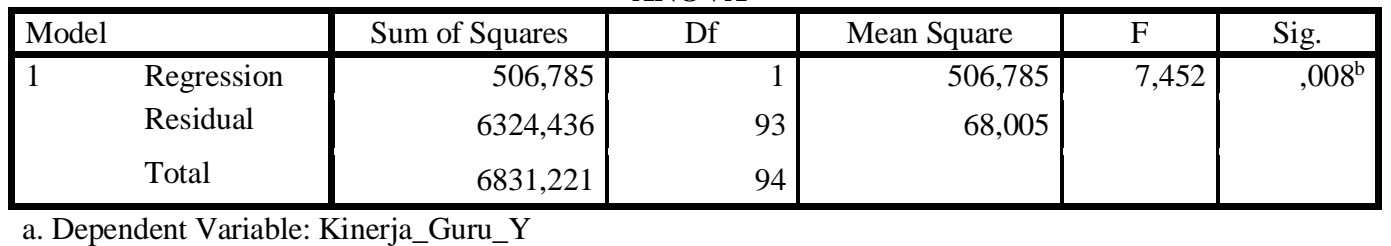

b. Predictors: (Constant), Budaya_Organisasi_X1

within an organization that interacts with

Berdasarkan tabel hasil uji anova atau $F$ test didapat $F_{\text {hitung }}$ sebesar 7,452 dan nilai signifikansi $0,008<0,05$. Dengan demikian $\mathrm{H}_{\mathrm{o}}$ ditolak artinya budaya organisasi terhadap kinerja guru pada SMP Negeri di Sektor 5 Kabupaten Indramayu adalah signifikan. Menurut Mondy, Sharplin \& Premeux (2005:450) yang menyatakan bahwa budaya organisasi merupakan "The system of shared values, beliefs, and habbits the formal structure to produce behaviour norms." (Suatu sistem berbagi atas nilai, keyakinan, dan kebiasaan di dalam suatu organisasi yang sesuai dengan struktur formal untuk menghasilkan norma-norma perilaku). Selanjutnya untuk mengetahui seberapa besar pengaruh budaya organisasi terhadap kinerja guru dapat dilihat dari hasil perhitungan koefesien determinasi pada tabel dibawah ini:

Tabel 2

\section{Besaran Pengaruh Variabel $X_{1}$ Terhadap $Y$}

\begin{tabular}{|l|r|r|r|r|}
\hline Model & $\mathrm{R}$ & $\mathrm{R}$ Square & Adjusted R Square & $\begin{array}{c}\text { Std. Error of the } \\
\text { Estimate }\end{array}$ \\
\hline 1 &, $272^{\mathrm{a}}$ &, 074 &, 064 & 8,246 \\
\hline
\end{tabular}


Dari tabel di atas terlihat bahwa $R$ Square sebesar 0,74, hal ini berarti bahwa $7,4 \%$ kinerja guru dipengaruhi oleh variabel budaya organisasi, sedangkan sisanya $92,6 \%$ dipengaruhi oleh faktor lain yang tidak diteliti.

\section{Pengaruh Motivasi Kerja Guru ( $\left.\mathbf{X}_{2}\right)$ terhadap Kinerja Guru (Y)}

Untuk mengetahui besaran pengaruh motivasi kerja guru $\left(\mathrm{X}_{2}\right)$ secara individual (parsial) terhadap kinerja guru (Y) dapat dilihat dari nilai t pada tabel Coefficients dibawah ini dengan kriteria pengujian jika tingkat signifikansi lebih kecil dari 0,05, maka hipotesis diterima. Adapun hasil pengujian hipotesis tersebut adalah sebagai berikut:

Tabel 3

\section{Uji Hipotesis ( $(t)$ Variabel $X_{2}$ terhadap $Y$}

Coefficients $^{\mathrm{a}}$

\begin{tabular}{|c|c|c|c|c|c|}
\hline \multirow[b]{2}{*}{ Model } & \multicolumn{2}{|c|}{$\begin{array}{c}\text { Unstandardized } \\
\text { Coefficients }\end{array}$} & \multirow{2}{*}{$\begin{array}{c}\text { Standardized } \\
\text { Coefficients } \\
\text { Beta }\end{array}$} & \multirow[b]{2}{*}{$\mathrm{t}$} & \multirow[b]{2}{*}{ Sig. } \\
\hline & $\mathrm{B}$ & Std. Error & & & \\
\hline $1 \quad$ (Constant) & 45,525 & 6,330 & & 7,192 &, 000 \\
\hline Motivasi_Kerja_Guru_X2 & ,423 & 091 & ,436 & 4,671 &, 000 \\
\hline
\end{tabular}

a. Dependent Variable: Kinerja_Guru_Y

Berdasarkan tabel hasil uji $t$ Persamaan regresi diperoleh = diperoleh bahwa nilai $t_{\text {hitung }}$ variabel $45,525+0,423 X_{2}$. Konstanta sebesar 45,525 motivasi kerja guru $\left(\mathrm{X}_{2}\right)$ memiliki nilai menyatakan bahwa jika ada kenaikan nilai sebesar $p$-value $0,000<0,05$ artinya dari variabel motivasi kerja guru $\left(\mathrm{X}_{2}\right)$, signifikan. Dengan demikian motivasi kerja kinerja guru (Y) adalah 45,525. Koefesien guru $\left(\mathrm{X}_{2}\right)$ secara parsial berpengaruh regresi sebesar 0,443 menyatakan bahwa terhadap kinerja guru (Y). Hal tersebut setiap perubahan satu skor atau motivasi mengandung makna diterimanya hipotesis yang menyatakan: "Terdapat pengaruh kerja guru akan memberikan skor 0,443.

Dari pengambilan keputusan yaitu positif dan signifikan motivasi kerja guru dengan membandingkan $\mathrm{F}$ hitung dengan terhadap kinerja guru pada SMP Negeri di Sektor 5 Kabupaten Indramayu ”. nilai $F$ tabel sebagai berikut: jika nilai signifikansi $<0,05$, maka Ho ditolak artinya koefesien regresi signifikan, dan sebaliknya. 


\section{Tabel 4}

\section{ANOVA $^{\text {a }}$ Variabel $\mathbf{X}_{2}$ terhadap $\mathbf{Y}$}

ANOVA ${ }^{\mathrm{a}}$

\begin{tabular}{|ll|r|r|r|r|r|}
\hline Model & & Sum of Squares & Df & Mean Square & F & Sig. \\
\hline 1 & Regression & 1298,158 & 1 & 1298,158 & 21,820 &, $000^{\mathrm{b}}$ \\
& Residual & 5533,063 & 93 & 59,495 & & \\
& Total & 6831,221 & 94 & & & \\
& & & & & \\
\hline
\end{tabular}

a. Dependent Variable: Kinerja_Guru_Y

b. Predictors: (Constant), Motivasi_Kerja_Guru_X2

Berdasarkan tabel hasil uji anova (2006:71) mengemukakan bahwa "Motivasi atau $\mathrm{F}$ test didapat $\mathrm{F}_{\text {hitung }}$ sebesar 21,820 dan kerja adalah suatu proses yang dilakukan signifikansi $0,000<0,05$ sehingga $\mathrm{H}_{\mathrm{o}}$ untuk menggerakan guru agar perilaku ditolak artinya pengaruh motivasi kerja guru mereka dapat diarahkan pada upaya-upaya terhadap kinerja guru pada SMP Negeri di yang nyata untuk mencapai tujuan yang Sektor 5 Kabupaten Indramayu adalah telah ditetapkan".

signifikan. Menurut Mulyasa (2003:112)

Selanjutnya untuk mengetahui "Motivasi adalah tenaga pendorong atau seberapa besar pengaruh motivasi kerja guru penarik yang menyebabkan adanya tingkah terhadap kinerja guru dapat dilihat dari hasil laku ke arah suatu tujuan tertentu. Sejalan perhitungan koefesien determinasi pada dengan pendapat Mulyasa, Hamjah tabel dibawah ini :

\section{Tabel 5}

\section{Model Summary Variabel $\mathbf{X}_{2}$ terhadap $\mathbf{Y}$}

Model Summary

\begin{tabular}{|l|r|r|r|r|}
\hline Model & R & R Square & Adjusted R Square & $\begin{array}{c}\text { Std. Error of the } \\
\text { Estimate }\end{array}$ \\
\hline 1 &, $436^{\mathrm{a}}$ &, 190 &, 181 & 7,713 \\
\hline
\end{tabular}

a. Predictors: (Constant), Motivasi_Kerja_Guru_X2

Dari tabel di atas terlihat bahwa $R$ dipengaruhi oleh faktor lain yang tidak Square sebesar 0,190, hal ini berarti bahwa diteliti.

$19 \%$ kinerja guru dipengaruhi oleh variabel motivasi kerja guru, sedangkan sisanya $81 \%$ 
Pengujian Hipotesis Pengaruh Budaya kinerja guru (Y) dapat dilihat dari nilai $\mathrm{t}$

Organisasi $\left(\mathrm{X}_{1}\right)$ dan Motivasi Kerja Guru

$\left(\mathrm{X}_{2}\right)$ Secara Bersama-sama terhadap Kinerja Guru (Y)

Untuk mengetahui besaran pengaruh budaya organisasi $\left(\mathrm{X}_{1}\right)$ dan motivasi kerja guru secara bersama-sama (ganda) terhadap pada tabel Coefficients dibawah ini dengan

kriteria pengujian jika tingkat signifikansi lebih kecil dari 0,05, maka hipotesis diterima. Adapun hasil pengujian hipotesis tersebut adalah sebagai berikut:

\section{Tabel 6}

\section{Uji Hipotesis ( $t$ ) Variabel $X_{1}$ dan $X_{2}$ terhadap $Y$}

Coefficients $^{\mathrm{a}}$

\begin{tabular}{|c|c|c|c|c|c|}
\hline \multirow[b]{2}{*}{ Model } & \multicolumn{2}{|c|}{$\begin{array}{c}\text { Unstandardized } \\
\text { Coefficients }\end{array}$} & \multirow{2}{*}{$\begin{array}{c}\begin{array}{c}\text { Standardized } \\
\text { Coefficients }\end{array} \\
\text { Beta }\end{array}$} & \multirow[b]{2}{*}{$\mathrm{t}$} & \multirow[b]{2}{*}{ Sig. } \\
\hline & $\mathrm{B}$ & Std. Error & & & \\
\hline $1 \quad$ (Constant) & 28,575 & 9,983 & & 2,862 &, 005 \\
\hline Budaya_Organisasi_X1 & ,294 & ,136 & ,202 & 2,168 & 033 \\
\hline Motivasi_Kerja_Guru_X2 & ,389 & ,090 & , 400 & 4,305 &, 000 \\
\hline
\end{tabular}

Berdasarkan tabel hasil uji $t$ diperoleh bahwa nilai thitung variabel budaya organisasi $\left(\mathrm{X}_{1}\right)$ dan motivasi kerja guru $\left(\mathrm{X}_{2}\right)$ secara bersama-sama (simultan) memiliki nilai sebesar $p$-value $0,000<0,05$ artinya signifikan. Dengan demikian budaya organisasi $\left(\mathrm{X}_{1}\right)$ dan motivasi kerja guru $\left(\mathrm{X}_{2}\right)$ secara bersama-sama (simultan) berpengaruh terhadap kinerja guru $(\mathrm{Y})$. Hal tersebut membuktikan diterimanya hipotesis yang menyatakan: "Terdapat pengaruh positif dan signifikan budaya organisasi dan motivasi kerja guru secara bersama-sama terhadap kinerja guru pada SMP Negeri di Sektor 5 Kabupaten Indramayu ".
Untuk mengetahui persamaan regresi dapat dilihat dari tabel di atas. Berdasarkan tabel tersebut menunjukkan persamaan regresi linier ganda:

$$
\widehat{Y}=28,575+0,294 X 1+0,389 X 2
$$

Persamaan tersebut menyatakan bahwa setiap penambahan $X_{1}$ dan $X_{2}$ sebesar 1 maka akan meningkatkan Y sebesar 0,294 dan 0,389 , artinya setiap peningkatan budaya organisasi dan motivasi kerja guru sebesar 1, akan meningkatkan kinerja guru sebesar 0,294 dan 0,389.

Dari pengambilan keputusan yaitu dengan membandingkan $\mathrm{F}$ hitung dengan nilai $F$ tabel sebagai berikut: Jika nilai 
signifikansi $<0,05$, maka Ho ditolak artinya

koefisien regresi signifikan, dan sebaliknya.

Tabel 7

ANOVA ${ }^{\text {a }}$ Variabel $X_{1}$ dan $X_{2}$ terhadap $Y$

ANOVA $^{\mathrm{a}}$

\begin{tabular}{|ll|r|r|r|r|r|}
\hline Model & & Sum of Squares & Df & Mean Square & F & Sig. \\
\hline 1 & Regression & 1567,090 & 2 & 783,545 & 13,694 &, $000^{\mathrm{b}}$ \\
& Residual & 5264,131 & 92 & 57,219 & & \\
& Total & 6831,221 & 94 & & & \\
& & & & & \\
\hline
\end{tabular}

a. Dependent Variable: Kinerja_Guru_Y

b. Predictors: (Constant), Motivasi_Kerja_Guru_X2, Budaya_Organisasi_X1

Berdasarkan tabel hasil uji anova atau F test didapat $F_{\text {hitung }}$ sebesar 13,694 dan signifikansi $0,000<0,05$ sehingga $H_{0}$ ditolak artinya pengaruh budaya organisasi dan motivasi kerja guru secara simultan terhadap kinerja guru pada SMP Negeri di Sektor 5 Kabupaten Indramayu adalah signifikan. Sutermeister (2000:45) berpendapat bahwa" ...we have recognized that empoyee performance depends on both ability and motivation". Selanjutnya diungkapkan bahwa: "Ability is deemed to result from knowledge and skill. Knowledge in turn is affected by education, experience, training and interest. Skill is affected by attitude and persoonality as well as by education, experience, training and interacting forces in physical condition of the joy and individual need." Dengan kata lain "performance" atau kinerja ditentukan oleh (1) kemampuan yang diperoleh dari hasil pendidikan, pelatihan, pengalaman, dan motivasi, yang merupakan perhatian khusus dari hasrat seorang pegawai dalam melaksankan suatu pekerjaan dengan baik.

Selanjutnya untuk mengetahui seberapa besar pengaruh budaya organisasi dan motivasi kerja guru secara simultan terhadap kinerja guru dapat dilihat dari hasil perhitungan koefesien determinasi pada tabel dibawah ini:

Tabel 8

\section{Model Summary Variabel $X_{1}$ dan $X_{2}$ terhadap $Y$}

Model Summary 


\begin{tabular}{|l|r|r|r|r|}
\hline & $\mathrm{R}$ & $\mathrm{R}$ Square & Adjusted R Square & $\begin{array}{c}\text { Std. Error of the } \\
\text { Estimate }\end{array}$ \\
\hline 1 &, $479^{\mathrm{a}}$ &, 229 &, 213 & 7,564 \\
\hline
\end{tabular}

a. Predictors: (Constant), Motivasi_Kerja_Guru_X2, Budaya_Organisasi_X1

Dari tabel di atas terlihat bahwa $R$ Square sebesar 0,229, hal ini berarti bahwa $22,9 \%$ kinerja guru dipengaruhi oleh variabel budaya organisasi dan motivasi kerja guru secara simultan, sedangkan sisanya $77,1 \%$ dipengaruhi faktor lain yang tidak diteliti.

\section{KESIMPULAN}

1. Secara empirik, hasil penelitian ini menginformasikan:

(1) terdapat pengaruh positif dan signifikan antara budaya organisasi terhadap kinerja guru pada SMP Negeri di Sektor 5 Kabupaten Indramayu, serta (2) besarnya kontribusi budaya organisasi terhadap kinerja guru pada SMP Negeri di Sektor 5 Kabupaten Indramayu ditunjukkan Persentase kontribusi budaya organisasi terhadap kinerja guru adalah sebesar $7,4 \%$, sementara sisanya dipengaruhi oleh variabel lain, selain variabel motivasi kerja guru, yang tidak dikaji dalam penelitian ini (epsilon).

2. Secara empirik, hasil penelitian ini menginformasikan: (1) terdapat pengaruh positif dan signifikan antara motivasi kerja guru terhadap kinerja guru pada SMP Negeri di Sektor 5 Kabupaten Indramayu, serta besarnya kontribusi motivasi kerja guru terhadap kinerja guru pada SMP Negeri di Sektor 5 Kabupaten Indramayu sebesar $19 \%$, sementara sisanya dipengaruhi oleh variabel lain, selain variabel budaya organisasi, yang tidak dikaji dalam penelitian ini (epsilon).

3. Secara empirik, hasil penelitian ini menginformasikan: (1) Terdapat pengaruh positif dan signifikan antara budaya organisasi dan motivasi kerja guru secara bersama-sama terhadap kinerja guru pada SMP Negeri di Sektor 5 Kabupaten Indramayu, serta Besarnya pengaruh budaya organisasi dan motivasi kerja guru terhadap kinerja guru pada SMP Negeri di Sektor 5 Kabupaten Indramayu secara bersamasama terhadap kinerja guru adalah sebesar $22,9 \%$, sementara sisanya dipengaruhi faktor lain yang tidak dibahas dalam penelitian ini.

\section{UCAPAN TERIMAKASIH}

Terimkasih kepada semua pihak yang telah membantu penulisan karya ilmiah ini.

\section{DAFTAR PUSTAKA}


Nurhaidah \& Musa, M.I. (2016). Pengembangan Kompetensi Guru Terhadap Pelaksanaan Tugas Dalam Mewujudkan Tenaga Guru Yang Profesional. Jurnal Pesona Dasar, Vol. 2 No.4, hal 8-27, April 2016.

Hasibuan, A.A. (2016). Manajemen Pembinaan Profesi dalam Pengingkatan Kinerja Guru (Studi di Madrasah Tsanawiyah DKI Jakarta). TANZHIM Jurnal Penelitian Manajemen Pendidikan, Vol.10, No.1, 2016

Manullang, Z.B \& Sibuea, A.M. (2017). Pengaruh Keteladanan Kepala Sekolah, Iklim Kerja Organisasi, Kepuasan Kerja Terhadap Loyalitas Kerja Guru SMP Kecamatan Medan Amplas. Jurnal Manajemen Pendidikan, Vol.9, No.2, Nopember 2017.

Munirah. (2015). Sistem Pendidikan Di Indonesia: antara Keinginan dan Realita. Auladuna, Vol. 2, No. 2 Desember 2015.

Falah, A. (2015). Studi Analisis AspekAspek Keberhasilan Pembelajaran Pendidikan Agama Islam di SDN 01 Karangmalang Gebog Kudus Elementary, Vol. 3, No. 1, JanuariJuni 2015.

Marwansyah dan Mukaram, (2002), Manajemen Sumber Daya Manusia, Bandung: Pusat Penerbitan Administrasi Niaga

Mondy, R., Wayne, Sharplin, Arthur, and Premeux, R. Shane. (2005). Management, Concepts, Practices, and Skills (Fifth ed). Massachusetts. Silmon \& Schuster, Inc.

Sutjipto. (2011). Rintisan Pengembangan Pendidikan Karakter di Satuan Pendidikan. Jurnal Pendidikan dan
Kebudayaan, Vol. 17, No 5, September 2011.

Lailatu Zahroh. (2015). Urgensi Pembinan Iklim dan Budaya Sekolah. Jurnal Pendidikan Agama Islam, Vol 3, Nomor 1, Mei 2015, Hal 162-186

Rasmi, R. (2014). Peningkatan Mutu dan Profil Lembaga Pendidikan Dalam Perspektif Total Quality Management (TQM). Jurnal Al-Ta'dib, Vol. 7, No. 1, Januari-Juni 2014.

Sukamto, Y \& Pardjono. (2016). Pengaruh Kompetensi Guru, Komitmen Kerja dan Motivasi Kerja Terhadap Kinerja Guru SMP Andalan di Sleman, Jurnal Penelitian Ilmu Pendidikan, Vol 9, No 2, September 2016.

Robbins. Stephen P. (2001). Organizational Behavior. Concept, Controversies and Application. 5th edition. Enalewood Cliffs. New Jersey: Prentice-Hall Int.

A.Dale Timple. (2011). Memotivasi Pegawai, Seri Manajemen Sumber Daya Manusia. Jakarta: Elex Media Komputindo.

Mulyasa, E. (2003). Menjadi Guru Profesional. Bandung: Remaja Rosdakarya

Hamzah B. Uno. 2006. Teori Motivasi dan Pengukurannya. Jakarta: Bumi Aksara Sutermeister. R. (2000). People and Productivity. New York: McGraw-Hill Book Company. 